MONOGRÁFICO: Materiales, transporte y producción. Pósters del Workshop Internacional de Arqueología de la Construcción V, (Universidad de Oxford, 11-12 Abril 2015 / MONOGRAPH: Materials, transport and production. Posters of the 5th International Workshop on the Archaeology of Roman Construction, (University of Oxford, April 11-12, 2015)

\title{
El transporte de grandes fustes monolíticos por el interior de la trama urbana de Roma
}

\section{Transporting large monolithic shafts through the interior of the city of Rome}

\author{
Patrizio Pensabene ${ }^{a}$ y Javier Á. Domingo Magañab \\ aLa Sapienza - Università di Roma \\ bPontificia Università della Santa Croce \\ e-mail: patrizio.pensabene@uniroma1.it; javdomingo78@gmail.com
}

\begin{abstract}
RESUMEN
Uno de los problemas que debe afrontar el estudio de los procesos constructivos ligados a la realización de proyectos arquitectónicos templares gigantescos en Roma es el de cómo se realizaba el transporte de grandes fustes monolíticos por el interior de la ciudad. De hecho, algunos templos, como el de Antonino y Faustina en el Foro Romano o el Foro de la Paz, fueron dotados de enormes fustes - respectivamente en cipollino y en granito rosa de Assuán- que tuvieron que atravesar la parte central de la ciudad cuya trama urbana ciertamente no facilitaba su transporte.

Intentaremos en nuestra intervención hipotetizar no sólo las posibles vías de transporte de estos enormes bloques sino también señalar las operaciones mecánicas necesarias para superar los frecuentes obstáculos que éstos encontrarían.
\end{abstract}

Palabras clave: transporte; columna; Roma.

\section{ABSTRACT}

One of the questions we have to answer when studying the process of building Rome's huge temples is how their large monolithic shafts were moved through the city. The shafts used in some of the temples were enormous. For example, the temple of Antoninus and Faustina in the Roman Forum and the Forum of Peace were built, respectively, with shafts of cipollino and granito rosa from Aswan. They would have had to have been taken through the city centre where manoeuvring such large loads through the narrow streets would not have been an easy task.

We will attempt to hypothesise not only the possible routes along which these enormous blocks were transported, but also the mechanical operations that would have been needed to overcome the frequent obstacles that would have been encountered.

Keywords: transport; columns; Roma.

Recibido: 09-06-2016. Aceptado: 13-07-2016.

Cómo citar este artículo / Citation

Pensabene, P., Domingo Magaña, J. A. 2016: "El transporte de grandes fustes monolíticos por el interior de la trama urbana de Roma", Arqueología de la Arquitectura, 13: e043. doi: http://dx.doi.org/10.3989/arq.arqt.2016.161

\section{Copyright}

(c) 2016 CSIC. Este es un artículo de acceso abierto distribuido bajo los términos de una licencia de uso y distribución Creative Commons Attribution (CC-by) España 3.0. 


\section{INTRODUCCIÓN}

La construcción de algunos edificios que podemos definir como gigantescos planteaba numerosas dificultades técnicas y logísticas, como las derivadas del transporte y alzado de los grandes y pesados fustes monolíticos presentes en muchos de ellos: consideramos gigantescos los fustes con una altura de entre 40-60 pies. Además, el paso de estos fustes por el interior de la trama urbana de las ciudades no hacía más que incrementar tales dificultades que debían afrontarse necesariamente con una precisa planificación de todas las acciones que dichas operaciones requerían. Pensemos, por ejemplo, en los enormes fustes del templo de Antonino y Faustina en el Foro Romano o del Aula de Culto del Forum Pacis — respectivamente en mármol cipollino y en granito rosa de Assuán- que tuvieron que cruzar una parte considerable de la ciudad hasta alcanzar el centro neurálgico de la urbs: el análisis de las dificultades derivadas del transporte de estos fustes, así como las posibles rutas urbanas seguidas, centrarán la última parte de este estudio.

De hecho, la peculiar trama urbana de Roma, con el predominio de callejones estrechos y frecuentemente en pendencia, debió dificultar enormemente este transporte ${ }^{1}$. Pero, al mismo tiempo, las dificultadas que este tipo de transporte debía afrontar provocaban la admiración de los ciudadanos, espectadores de un despliegue técnico y de fuerzas que magnificaban irremediablemente el poder y prestigio de los comitentes (DeLaine 2002: 213-214): Plinio el Viejo, por ejemplo, narra la admiración provocada por el transporte de los obeliscos a Roma y de los enormes bloques de piedra destinados al entablamento del templo de Artemisa en Éfeso (Plin., NH 36.14.64-72 y 36.21.95-97), mientras que Amiano Marcelino se recrea en la construcción de una nave expresamente diseñada para el transporte del obelisco colocado en la espina del Circo Máximo en Roma (17.4.13-15), sobre el que volveremos más adelante, y Teodosio hizo inmortalizar en un relieve situado en la base de su obelisco en Constantinopla las complejas operaciones realizadas para el transporte y alzado de este monumento (Pensabene 2013: 259-260).

Como contrapartida, el transporte de los grandes monolitos generaba también importantes molestias: Plinio, por ejemplo, cita como el paso por las calles de Roma de una serie de columnas de 38 pies de altura provocó

\footnotetext{
1 Un desnivel del $5 \%$ podía hacer que el transporte fuera muy peligroso y mucho más complejo: un desnivel del $1 \%$ podía implicar duplicar el número de animales de tiro (Russell 2013: 100-101).
}

innumerables daños en las cloacas que hubo que reparar (Plin., N. H. XXXVI, 6-7) (Barresi 2000: 340), mientras que Juvenal recuerda el peligro que el transporte de bloques de mármol podía representar para los peatones (Juvenal, Sátiras, III, 256-261) y el insoportable ruido que hacían los pesados y molestos carros que transitaban por las estrechas calles de la ciudad (Juvenal, Sátiras, III, 236-237)²; un transporte, el de los bloques de piedra y otros elementos necesarios para la construcción, que tenía lugar principalmente durante las horas diurnas, a diferencia de otras mercancías que debían hacerlo de noche ${ }^{3}$, interrumpiendo por tanto el tráfico en una ciudad ya de por sí bastante caótica y congestionada.

Las dificultades derivadas de la manipulación de grandes y pesados bloques de piedra comenzaban ya en el momento de su extracción en la cantera. En otra sede hemos visto como la estandarización de las medidas que se observa en algunos elementos arquitectónicos gigantescos podría ser debida en parte a la necesidad de disponer de complejos sistemas mecánicos de extracción, elevado y transporte expresamente diseñados para ellos, cuyo peso y volumen serían por tanto parecidos. Esto explicaría en parte la exigencia que se verificó en las capitales provinciales de imitar la arquitectura de Roma, y en Roma misma de replicar o al menos de acercarse a las medidas del elevado arquitectónico del templo de Mars Ultor (Pensabene y Domingo 2014: 118-121).

Pero en estos primeros estadios de la producción (extracción de los bloques en la cantera y primeras etapas de su elaboración) las operaciones de maniobrabilidad contarían con la ayuda de voluminosos y complejos sistemas mecáni$\cos$ - estos resultaban absolutamente imprescindibles para llevar a cabo determinados proyectos arquitectónicospues los espacios libres disponibles en las canteras, o quizás expresamente reservados para ellos, permitían el despliegue de tales infraestructuras. Además, las rutas seguidas para el transporte de los fustes gigantescos estaban provistas generalmente de todos los servicios necesarios para el desarrollo de esta actividad. Por ejemplo, en el desierto egipcio se conoce una importante red de fortines colocados en los puntos

“¿Qué pensión permite el sueño? En la ciudad (Roma) hay descanso para las grandes fortunas. Ahí está la causa de la enfermedad: el trasiego de las ruedas en la estrechez y cruce de las calles y el encuentro de las cuadrillas de carreteros arrebatará el sueño a Druso y a las vacas marinas».

3 Una ley dictada por Julio César, que sabemos todavía vigente en tiempos de los flavios y Trajano, permitía el transporte de bloques de piedra y otros elementos necesarios para la construcción durante las horas diurnas, (Carcopino 2007: 61-63).

4 La necesidad de crear una gran cantidad de bloques de piedra podría ser la causa también de la estandarización de las medidas de los bloques en tufo que se documenta ya desde la aparición de la opera quadrata en Roma hacia finales del s. VII a.C., (Cifani 2010: 41). 
de parada previstos para el reposo de los animales de tiro, una red que permite conocer el número de $\mathrm{Km}$ que podían recorrer en un día estos animales y el número de bestias de carga necesario en función del peso transportado ${ }^{5}$.

Otras máquinas debían disponerse en los puertos de llegada de los grandes bloques, para facilitar las operaciones de elevación y desembarco. El puerto de las canteras del sector de Aliki en Tasos, por ejemplo, ofrece el testimonio - a través de los agujeros conservados en el muelle - de la existencia de grúas con ruedas movidas por fuerza humana, probablemente similares a la que se representa en el conocido relieve de los Haterii de Roma, donde la rota para el enrollado de las cuerdas que regulaba la inclinación del cabrestante tenía como fuerza motriz a hombres que caminaban en su interior (rota calcatoria). En el caso de fustes de pequeñas dimensiones, las operaciones de elevación podían hacerse mediante el uso de tenazas de hierro o, como muestra otro relieve de Capua, mediante la presencia de un collarín a una cierta altura del fuste, en el que podían ligarse varias cuerdas para tirar de los objetos (Taylor 2006: 125, fig. 54).

\section{LA LLEGADA A LA CIUDAD}

El punto de llegada y desembarco de los grandes elementos arquitectónicos dependía de las posibilidades de maniobrar estos monolitos, del lugar de destino de las piezas transportadas y de las posibles rutas que podían seguir dichos elementos por el interior de la trama urbana de la ciudad. Es necesario señalar ahora que a diferencia del transporte de bloques de mármol, que sabemos llegaban a Porto, donde podían ser almacenados y embarcados periódicamente en naves más pequeñas que remontaban el Tíber hasta Roma en función de las necesidades que se producían, los fustes monolíticos gigantescos tenían que ser transportados directamente a su lugar de destino, debido principalmente a dos motivos:

1) En primer lugar, no parece lógico pensar que los bloques gigantescos fuesen almacenados en algún depósito marmorario a la espera de ser utilizados en alguna construcción que pudiese necesitarlos, como sí sabemos que sucedía, por ejemplo, con elementos arquitectónicos más pequeños; quizás incluso con fustes de hasta 20

\footnotetext{
5 De hecho, los varios poderes que se sucedieron en Egipto se preocuparon de construir calles y puntos de parada y reposo en el desierto oriental y en los puertos del Mar Rojo (Strab., 17.1.45).
}

pies de altura almacenados en un primer momento en Porto y paulatinamente transportados a Roma en naves más pequeñas, como mostraría un relieve hoy en el Louvre (Paris, Louvre MA 593; Maischberger 1997: 29 , nota 129$)^{6}$. Además, el gran tamaño de los fustes hacía poco rentable económicamente someterlos a demasiados cambios de medio de transporte y su elevado coste hacía poco factible su adquisición para tenerlos almacenados sin un uso todavía claro. De hecho, en los depósitos de Roma, Porto y Ostia raramente se encuentran fustes almacenados mayores de $5 \mathrm{~m}$ de altura ${ }^{7}$.

Por tanto, los fustes gigantescos eran importados para ser utilizados en proyectos arquitectónicos concretos que ya estaban en construcción, y eran transportados directamente a su lugar de destino. Una operación esta última que debía coordinarse perfectamente con el desarrollo del proceso constructivo, previendo por tanto la disposición del espacio necesario para su maniobrabilidad, la preparación de los entablamentos que debían apoyarse encima de estas columnas y la construcción de los muros circundantes encima de los cuales debían encajar estos elementos sustentantes (Taylor 2006: 134136). Podemos citar, a modo de ejemplo, la fachada del Panteón, diseñada en el proyecto original para albergar columnas con fustes de 50 pies de altura. Según una hipótesis de R. Taylor (Taylor 2006: 138-141) las $^{8}$

\footnotetext{
En este sentido, podemos citar el hallazgo de una pequeña nave que transportaba dos bloques de piedra, tallados en placas, por el Ródano. Para cargas más pesadas se podría pensar en la presencia de naves con fondo plano, sin quilla, diseñadas para el transporte por río. De todos modos, esta tipología de barca no ha sido documentada en Roma ni en fuentes escritas ni arqueológicas, pero sabemos que existía en Dalmacia, en Galia y en Germania, (Maischberger 1997: 30). De todos modos, los fustes de columna gigantesca eran demasiado pesadas para este tipo de transporte.

Podemos citar algunos ejemplos: en el depósito localizado en el Templo de los Fabri Navales los fustes conservados presentan una altura que va de los 2,01 m a los 3,55 m (Pensabene 1994: 36); en el almacén del Canale di Fiumicino los fustes, en mármol africano, pavonazzetto, cipollino, portasanta y fior di pesco, no superan los 4,30 m de altura (Pensabene 1994: 53-117, $\mathrm{n}^{\circ}$ 3, 4, 18, 19, 34, 35, 37, 39, 50); en al almacén de via Redipuglia un sólo fuste entero presenta una altura de 2,88 m (Pensabene 1994: 133, n 80); en el almacén del edificio fuori Porta Marina los fustes, en africano, cipollino y breccia rosata appeninica, presentan una altura que no supera los 3,00 m (Pensabene 1994: 156-157, $\mathrm{n}^{\circ}$ 97, 99-104); en el almacén detrás del Museo delle Navi los fustes, en fior di pesco, no superan los 2,32 m de altura (Pensabene 1994: 158, nº 114-115); en el almacén de la Tenuta Sforza Cesarini los fustes conservados, en cipollino y proconnesio, no superan los 4,74 m de altura (Pensabene 1994: 178-183, n 122, 127, 140-149, 153-156, 158-160, 163-164); en el almacén de via Ostiense en Roma los fustes conservados, en cipollino, africano, bigio africano, alabastro fiorito, breccia pavonazza chiara e breccia corallina, no superan los 4,29 m de altura (Pensabene 1994: 216-249, no 33-36, 42-43, 45-46, 48, 51-52).

8 Hay que señalar que acerca del problema de la superposición de los tímpanos en el Panteón se han formulado numerosas hipótesis (Wilson Jones 2009: 199206, 208-210). Incluso se ha sugerido recientemente que podría responder a una cuestión estética (Giuliani 2015: 146).
} 
columnas no llegaron a su destino en el tiempo previsto, sino que lo hicieron cuando la construcción de la gran rotonda ya había comenzado. En este momento, ya avanzados los trabajos, no existiría el espacio suficiente para elevar fustes de 50 pies de altura, motivo por el cual fue necesario sustituirlos por otros más pequeños, de 40 pies.

2) En segundo lugar, sabemos que el transporte de elementos arquitectónicos gigantescos, cuando superaban las 300-350 toneladas de peso, requerían el uso de naves expresamente adaptadas para ellos (Maischberger 1997: 28-29). Algunos naufragios nos permiten conocer la capacidad de carga de diversas naves encargadas del transporte de mármoles, generalmente entre las 200-350 toneladas 9 . A partir de éstos y otros datos D. Rathbone cree que en el s. I-II d.C. las naves que efectuaban los viajes más lejanos — cargadas muchas veces con vino, grano o mármoles-, tenían una capacidad media de carga de unas 200-400 toneladas (Rathbone 2003: 199201), una longitud media de 30-40 $\mathrm{m}$ y una anchura de unos $14 \mathrm{~m}$. Son medidas éstas equivalentes por tanto a una nave con una capacidad de carga de no más de dos fustes de 50 pies de altura $(15 \mathrm{~m})$ y un peso de 96 toneladas, o no más de 4 fustes de 40 pies de altura $(11,8 \mathrm{~m})$ y un peso de 50 toneladas (Pensabene 2013: 259).

Otros datos acerca del punto de llegada de los grandes monolitos a Roma nos los ofrece el transporte de al-

\footnotetext{
9 Entre los naufragios mejor conocidos podemos citar el de Mahdia, del 110-90 a.C., con una capacidad de carga de unas 250 toneladas (Medaglia, Beltrame y Lazzarini 2013: 147); el de Porto Novo, de época de Tiberio, con una carga de elementos arquitectónicos formada por cuatro columnas de 1,5 m de diámetro, cinco bloques de más de 2,5 $\mathrm{m}$ de lado y un peso cada uno de 6-6,3 toneladas y algunas placas de mármol, por un peso total de 138 toneladas (Bernard, Bessac, Mardikian, Feugère 1998: 53-54); el de St. Tropez A, del s. II d.C., con una capacidad de carga de unas 200-230 toneladas; el de Torre Sgarrata, del 180-205 d.C., con una capacidad de carga de unas 160 toneladas; el de Marzamemi A, de la primera mitad del s. III d.C., con una capacidad de carga de unas 200 toneladas; el de S. Pietro, de la primera mitad del s. III d.C., con una capacidad de carga de unas 150 toneladas (Medaglia, Beltrame y Lazzarini 2013: 147); el de Punta Scifo D, del s. III d.C., que transportaba 54 bloques de mármol de varias dimensiones con un peso total de 340 toneladas (Medaglia, Beltrame y Lazzarini 2013: 144-146); el de Punta Scifo A, de la segunda mitad del s. III d.C. o de inicios del s. IV d.C., con una capacidad de carga de unas 300 toneladas; el de Capo Granitola A, del 225-275 d.C., con una capacidad de carga de unas 150 toneladas (Medaglia, Beltrame y Lazzarini 2013: 147); el de la Isola delle Correnti, del s. III-IV d.C., con una capacidad de aproximadamente 340 toneladas (Hopkins 1983: 98); y el de Sapientza, de época tardorromana o bizantina, con una capacidad de carga de unas 300 toneladas (Medaglia, Beltrame y Lazzarini 2013: 147). Otras naves naufragadas que transportaban mármoles, aunque con una capacidad de carga inferior, en: Russell 2011: 139-155. Conocemos otras naves que transportaban otros productos, como el naufragio de Madrague de Giens, de hacia mediados del s. I a.C., con una capacidad carga de 350 toneladas, o el de Albenga, del s. I a.C., que transportaba ánforas, con una capacidad de carga de 450 toneladas (Bernard, Bessac, Mardikian, Feugère 1998: 53-54).
}

gunos obeliscos. Sabemos, por ejemplo, que Augusto hizo transportar un obelisco destinado al Circo Máximo, de 24 $m$ de altura y 440 toneladas de peso, hoy en la Piazza del Popolo (Plinio, N. H., 36, 70). Sabemos que Calígula hizo transportar otro obelisco para su circo en el Vaticano, de $25 \mathrm{~m}$ de altura y un peso de 325 toneladas (Plin., N. H., 16, 201-202), hoy en la plaza de San Pedro, que precisó de una nave expresamente diseñada que atracó en el puerto de Ostia; nave que más tarde fue reutilizada por Claudio en la construcción del faro de su nuevo puerto (Suet., Claud., 20,3). Y, finalmente, sabemos que Constancio II hizo transportar al Circo Máximo de Roma en el 357 d.C. el obelisco que Constantino dejó en Alejandría, con una altura de $32 \mathrm{~m}$ y un peso de unas 350 toneladas $^{10}$, hoy en San Juan de Letrán. Este obelisco precisó de una nave expresamente diseñada que remontando el Tíber llegó hasta 3 millas al sur de la ciudad, como narra detalladamente Amiano Marcelino (17, 4, 14-15)"11: "El obelisco fue transportado a través del canal del Nilo hasta Alejandria; alli fue construida una nave de dimensiones hasta entonces desconocidas, propulsada por trescientos remos. Llegado a Ostia fue hecho remontar con grandes dificultades el Tiber hasta el Vicus Alexandri distante tres millas de la ciudad. El obelisco fue puesto luego sobre trineos y con gran atención se hizo pasar por la Puerta Ostiense y a través de la Piscina Pública fue llevado al Circo Máximo”. Por tanto, la nave consiguió remontar con grandes dificultades el Tíber pero sólo hasta 3 millas al sur de la ciudad, donde el obelisco tuvo que ser desembarcado, quizás a causa de las dimensiones de la nave o a la insuficiente profundidad del Tíber (Maischberger 1997: 29), y llevado a Roma por tierra a través de la vía Ostiense hasta el Circo Máximo. Ningún indicio, por tanto, permite pensar en el transporte de estos pesados elementos en naves más pequeñas a su llegada a la costa.

A partir de los datos relativos al transporte de estos obeliscos se aprecia una significativa diferencia entre la época de Augusto-Calígula - la nave que transportaba el obelisco para el Circo Máximo permaneció en el puerto de Ostia - y la época de Constancio II — la nave utilizada consiguió remontar gran parte del Tíber-. Y esta diferencia podría derivar, entre otros motivos, de la construcción del Puerto de Claudio, inaugurado en el 64 d.C., y del puerto de Trajano y la Fossa Traiana (Canale di Fiumicino), que hicieron más fácil la navegación del

\footnotetext{
10 Acerca de este obelisco: Maischberger 1997: 28-29.

11 Podemos añadir que Procopio (Gotica, 1, 26) dice que en el s. VI d.C. algunas naves que viajaban por el Tíber eran tiradas por bueyes o hombres.
} 
Tíber hasta Roma. Además, muy probablemente también en época de Trajano se construyó el denominado Canale Romano, de $35 \mathrm{~m}$ de anchura y unos 5-7 m de profundidad, situado entre el Tíber y la Fossa Traiana, que permitiría la navegación de embarcaciones cargadas hasta con 350-390 toneladas de peso (Salomon, Goiran, Bravard, Arnaud, Djerbi, Kay y Keay 2014: 31-49, fig. 1 у 6 ).

De todos modos, es necesario tener en cuenta que la llegada de los grandes bloques de piedra era siempre una operación muy compleja sujeta a las condiciones de navegabilidad del Tíber en su paso por la ciudad, unas condiciones que variarían en función de las estaciones del año, más o menos lluviosas, y por tanto del cabal de agua transportado. No podemos excluir la posibilidad que el transporte de cargas muy pesadas por el río fuese diferido al momento en el que el nivel de cabal de agua era más elevado, en otoño o invierno, para permitir el paso de las naves de mayor tamaño; un periodo que no necesariamente coincidía con el momento de llegada de la nave al puerto. Además, una confirmación de la llegada directa a Roma de grandes bloques nos la ofrece en época de Adriano la zona del mausoleo de Augusto, delante del cual se conservan las marcas de la preparación, y quizás también del corte, de los gigantescos bloques de piedra destinados al entablamento del Panteón; aunque quizás la zona fue adaptada para tal uso sólo de manera provisional para este edificio (Wilson Jones 2009: 206-207) o quizás también, y siempre de manera puntual, para la construcción de otros importantes edificios (Haselberger 1994: 299) ${ }^{12}$, que suponemos debieron erigirse en esta zona del Campo de Marte.

\section{EL TRANSPORTE DENTRO DE LA CIUDAD}

Como ya hemos señalado anteriormente, las mayores dificultades que debía afrontar el transporte de los grandes fustes se presentaban en el interior de la trama urbana de las ciudades, con calles cuyas dimensiones no siempre permitían el uso de los complejos sistemas mecánicos que habrían facilitado enormemente tales operaciones. Roma no era ciertamente una excepción y ya Tácito, por ejemplo, atribuyó a la anarquía de sus calles cerradas y sinuosas la rapidez con que se propagó el incendio del 64 d.C. (Tac., Ann. XV, 38 e 43). Pocas calles permitían

\footnotetext{
12 Haselberger señala como posibles edificios que podrían haber utilizado esta zona el Templo de Matidia y el Templo de Venus y Roma.
}

de hecho el paso de dos carros a la vez - dentro de las murallas republicanas sólo dos, la via Sacra, de 4,8 m de anchura, aunque en su entrada al Foro Romano podía alcanzar los $10 \mathrm{~m}$, y la via Nova, de 6,5 m, aunque muy probablemente ésta debió desaparecer con motivo de las reformas realizadas tras el incendio neroniano (Coarelli 2012: 94) - pues la mayoría de ellas presentaban una anchura de apenas 2,9 m (Carcopino 2007: 57) ${ }^{13}$. Podemos incluir en este elenco la via Lata, el tramo de via Flaminia que pasaba por el interior de la ciudad, entre la porta Fontinalis y la porta Flaminia (Patterson 1999: 139-140), cuya anchura alcanzaba los 6,5 m.

Con todos estos datos queremos ahora analizar las posibles rutas urbanas utilizadas para el transporte de los grandes fustes monolíticos de dos edificios que por su localización, en el entorno del Foro Romano, obligaron a estas piezas a atravesar gran parte de la trama urbana de la ciudad: el templo de Antonino y Faustina y el Aula de Culto del Templum Pacis. Hemos visto como la construcción de los puertos de Claudio y Trajano pudo favorecer que los bloques gigantescos alcanzasen la ciudad por dos vías: el sur, por tierra a través de la vía Ostiense, o el norte, remontando el Tíber hasta la zona del Campo de Marte. A estas dos posibles rutas podemos añadir la propuesta realizada por E. Bianchi y R. Meneghini para el transporte de los fustes gigantescos destinados muy probablemente al templo de Trajano, con una altura de unos $15 \mathrm{~m}$ y un peso cada uno de unas 107 toneladas. Según estos autores, los fustes podrían haber remontado el Tíber hasta la altura del Aventino, alcanzando posteriormente la zona del Foro de Trajano pasando o bien por el Velabro, el clivo Argentario y el vico Iugario, o bien rodeando el Capitolio por el lado norte (Bianchi y Meneghini 2002: 405, fig. 9). De todos modos, esta propuesta, que parece factible para el transporte de las columnas utilizadas en el Foro de Trajano, pues rodeando el Capitolio alcanzarían fácilmente este conjunto arquitectónico y/o cruzando la zona del Foro Romano alcanzarían el de Trajano sin necesidad de realizar ningún giro (en tiempos de Trajano el Foro de César fue remodelado y, por tanto, probablemente no constituiría un obstáculo para el paso de las columnas [Amici 1991: 75-136]), plantearía en cambio algunas dificultades si se quisiera alcanzar el templo de Antonino y Faustina o el Aula de Culto del Templum Pacis: en ambos casos los fustes deberían haber entrado en el foro por el vicus Iugarius y haber realizado

\footnotetext{
13 Las calles podían denominarse itinera, si eran accesibles sólo a peatones, actuas, si podía pasar un solo carro a la vez, y viae, si permitían el paso de dos carros a la vez.
} 
inmediatamente un complicado giro de casi $90^{\circ}$ sorteando de algún modo los Rostra (Coarelli 1999: 212-214; Verduchi 1999: 214-217).

Por otro lado, y por lo que se refiere al transporte de bloques de mármol de pequeñas y medianas dimensiones, podemos citar como una posible vía para el transporte el Euripus, un canal artificial de agua que recorría desde época de Augusto y hasta al menos la época de Adriano, el Campo de Marte hasta el Stagnum Agrippae (Pentiricci 2009: 32-34). Este canal tenía una anchura de $3,35 \mathrm{~m}$ y una profundidad de $1,40-2,00 \mathrm{~m}$, con una sección en el fondo semicircular y en determinados tramos trapezoidal (Coarelli 1977: 830) ${ }^{14}$, por lo que permitía sólo el paso de pequeñas naves. En torno a este canal se encuentran numerosos depósitos de mármol, formados por piezas de pequeña entidad ${ }^{15}$, que demostrarían su uso también para este tipo de transporte.

En la elección de una u otra ruta jugarían un papel destacado el peso y las dimensiones de los elementos transportados (algunos, los más pesados, muy probablemente no podrían remontar el Tíber hasta la zona del Campo de Marte) y el lugar de destino de los bloques, buscando siempre la ruta más breve y evitando el paso por calles demasiado estrechas, sinuosas o en pendencia.

Por lo que respecta a los fustes de los edificios objeto de nuestro estudio, veremos que su transporte por vía fluvial no habría implicado grandes problemas ${ }^{16}$. De hecho, los fustes del templo de Antonino y Faustina, de mármol cipollino, con una altura de $11,8 \mathrm{~m}$ y un diámetro en el imoscapo de 1,48 m, debían tener un peso cada uno de aproximadamente 50-55 toneladas ${ }^{17}$ (Fig. 1). Los fustes de la fase severiana del Aula de Culto del Forum Pacis, de granito rosa de Assuán, con una altura de $15 \mathrm{~m}(=50$ pies) y un diámetro de imoscapo de $1,75 \mathrm{~m}^{18}$, debían tener

\footnotetext{
14 Sobre las últimas novedades y hallazgos de este canal ver: Filippi 2014: 53-70. 15 Como el localizado en la zona del Palazzo della Cancelleria, del que proceden elementos arquitectónicos de época de Domiciano; el localizado no muy lejos, en el corso Vittorio Emanuele, del que proceden cuatro capiteles; el hallazgo de estatuas y elementos arquitectónicos en la zona de la Chiesa Nuova; el hallazgo de una estatua de un Dacio en via del Governo Vecchio; el hallazgo al sur de este canal de diversos bloques de travertino con molduras no terminadas debajo de un estrato de tierra de época flavia (Pentiricci 2009: 56, 62); así como otros hallazgos dispersos (Maischberger 1997: 155).

16 Las columnas del Panteón, por ejemplo, de 40 pies de altura y 55 toneladas de peso, podrían haber viajado en una nave con capacidad para cargar entre dos y cuatro fustes (Fant 2012: 530-531).

17 El volumen máximo de mármol utilizado en el fuste $\left[\pi \mathrm{r}^{2} \cdot \mathrm{h}\right]$ era de $20,3 \mathrm{~m}^{3}$ x $2.726 \mathrm{Kg} / \mathrm{m}^{3}$ de cipollino (Pegoretti 1869: 267-266) = 55 toneladas, pero no siendo el fuste cilíndrico esta cifra debe reducirse ligeramente.

18 Parece que la restauración de este monumento tras el incendio del 192 d.C. respetó las dimensiones de los elementos arquitectónicos de la fase
}

un peso cada uno de aproximadamente 140 toneladas $^{19}$ (Fig. 2).

En ambos casos es factible suponer su llegada a la ciudad tanto por tierra, a través de la vía Ostiense, como en naves que remontando el Tíber habrían alcanzado sin demasiados problemas la zona del Campo de Marte. La elección de la ruta seguida, por tanto, dependería del lugar de destino de los fustes y del medio de transporte utilizado para moverlos, teniendo en cuenta las mayores o menores dificultades que ofrecía el paso por determinados espacios urbanos. De hecho, y a diferencia de cuanto ocurría con el transporte de pequeñas columnas, que podían ser cargadas encima de carros - un carro podía transportar fustes de hasta 30 toneladas y 30 pies de altura (Bülow-Jacobsen 2009: 206), aquéllos no muy pesados dispuestos a veces ligeramente inclinados, como muestra un mosaico tardoantico de Oued R'mel, ahora en el Museo del Bardo en Túnez (Russell 2013: 98, fig. 4.1) - el transporte de grandes fustes no siempre permitía esta solución, pues el propio peso de los elementos transportados habría dañado las ruedas o provocado su bloqueo en cualquier irregularidad del terreno. Vitruvio $(10,2,11)$ nos ilustra sobre estas dificultades:

Queriendo transportar desde las canteras hasta el templo de Diana en Éfeso los fustes de unas columnas, ante la duda de que, dada su magnitud y su peso y la poca solidez de los caminos, se hundiesen las ruedas de los carros (...).

Por tanto, hemos de suponer su transporte mediante trineos de madera, deslizándose sobre troncos a través de planos inclinados (Adam 2011: 30, fig. 31), que precisaban de un terreno poco abrupto y preferiblemente con pocos desniveles. Así fueron transportados, por ejemplo, los bloques de piedra del trilithon del templo de Júpiter en Baalbek (Adam 2011: 32, fig. 36), el obelisco traído por Constancio II a Roma y, más recientemente, el obelisco de Mussolini en Roma (Fig. 3). Pero este sistema requería además de una gran fuerza de tracción, formada por un numeroso conjunto de hombres o animales que debían disponerse por el interior de la trama urbana de Roma: un bloque de 20 toneladas debía ser tirado por 12-15

flavia (Rizzo 2001: 241; Meneghini, Corsaro y Pinna 2009: 199; Fogagnolo y Rossi 2010: 96).

19 El volumen máximo de granito utilizado en el fuste era de $50,52 \mathrm{~m}^{3} \mathrm{x}$ $2.833 \mathrm{Kg} / \mathrm{m}^{3}$ de granito rosa de Assuán (Pegoretti 1869: 267-266) = 143,1 toneladas, pero no siendo el fuste cilíndrico esta cifra debe reducirse ligeramente. 


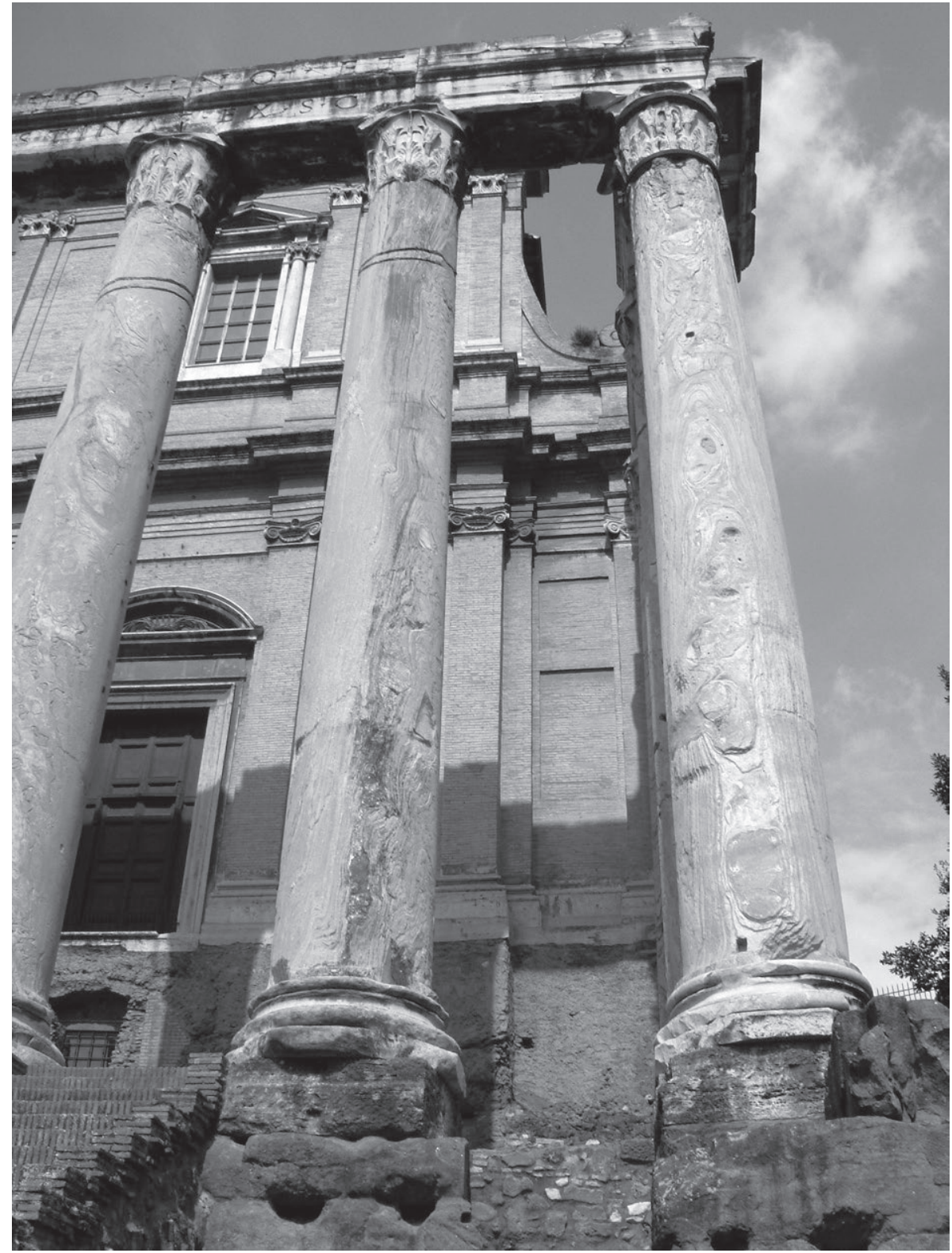

Fig. 1. Columnas, en mármol cipollino, del templo de Antonino y Faustina. hombres (Marano 2014: 422) ${ }^{20}$, por lo que el transporte de los fustes del templo de Antonino y Faustina y del Aula de Culto del Forum Pacis requeriría de una fuerza notablemente mayor ${ }^{21}$; unos 30 bueyes para mover cada

20 Este fue muy probablemente el sistema de transporte utilizado para un fuste de columna de 50 pies de altura destinado probablemente al templo del Divo Traiano en Roma (Theodore Peña 1989: 129).

21 Un papiro (P. Gis 69) informa de las dificultades de gestionar y alimentar el gran número de animales necesario para transportar en el 118 d.C. un fuste de columna de 50 pies de altura por el desierto egipciano, muy probablemente destinado al templo del Divo Traiano de Roma (Theodore Peña 1989: 126132). No tenemos datos ciertos acerca del número de animales de tiro que servían para transportar determinados pesos, ya que su número dependía de las condiciones del transporte y del terreno, de la pendencia de las calles, de la distancia a recorrer, etc. (Adam 2001: 174), pero podemos citar algunos ejemplos: uno de los fustes del templo de Antonino y Faustina y de unos 100 bueyes para mover los fustes del Aula de Culto del Forum Pacis. Una imagen del transporte del obelisco

sabemos que a inicios del sec. XX, en Carrara, carros de cuatro ruedas tirados por doce bueyes podían transportar 9 toneladas de peso (Russell 2013: 98); en otros casos sabemos que una pareja de bueyes podía tirar un carro con un peso de unos $700 \mathrm{Kg}$ (Boato 2007: 225-226); mientras que en otras circunstancias la carga transportada era inferior (DeLaine 1997: 107-108) o superior, hasta alcanzar los $900 \mathrm{Kg}$ (Jodin 1987: 251), 1 tonelada (Adam 2001: 174), 1,5 toneladas (Prisset 2008: 128) o 2,7 toneladas (Pegoretti 1869: 37). Para transportar los bloques del trilithon del templo de Júpiter en Baalbek, de 800 toneladas cada uno, fueron utilizados 800-825 bueyes (Adam 2011: 55-56), mientras que para mover el obelisco de Mussolini, de $32 \mathrm{~m}$ de altura y un peso de 560 toneladas, transportado cuesta abajo desde la colina de Carrara hasta Marina de Carrara, bastaron 60 bueyes (Adam 2011: 30). 


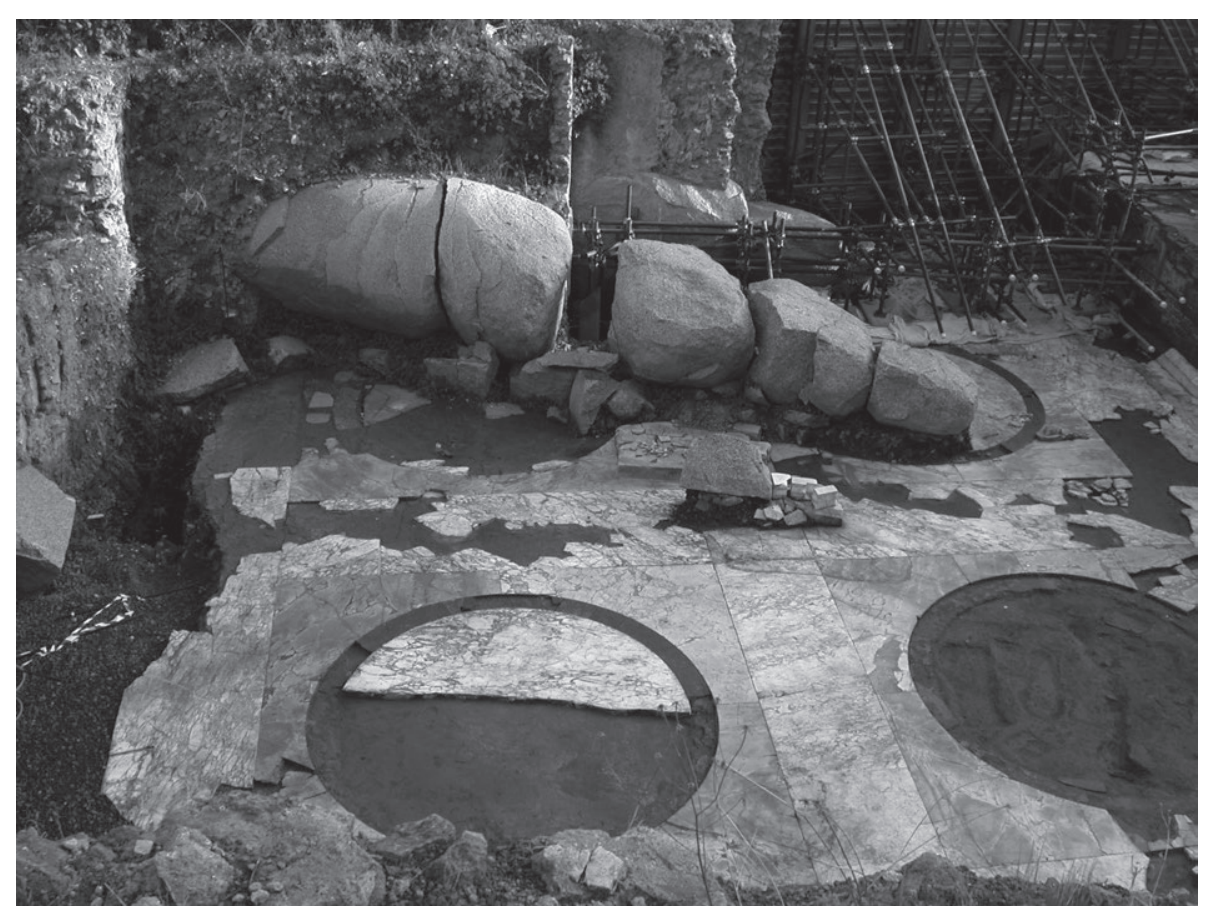

Fig. 2: Columnas, en granito rosa de Assuán, del Aula de Culto del Templum Pacis. dedicado a Mussolini en el Foro Italico de Roma, de 39,56 m de altura y realizado en mármol de Carrara (el pedestal que sustenta el obelisco fu realizado con 16 bloques de mármol), transportado por 100 bueyes, permite hacernos una idea de la dificultad que suponía la disposición en fila de todos los animales de tiro necesarios por el interior de las calles de una ciudad (Fig. 4). Este despliegue contaría puntualmente con la ayuda de maquinaria dispuesta allí donde las condiciones de las calles lo permitiesen y muy probablemente bajo la atenta supervisión de un grupo de arquitectos: de algunas inscripciones que aparecen sobre fustes en el desierto oriental egipcio sabemos que las grandes máquinas tractorie y elevatorie dotadas de poleas y tornos para la elevación de las columnas gigantescas, como las que describe Vitruvio (10, $1,1 \mathrm{ss}$ ), eran proyectadas por arquitectos (Dubois 1908: $\mathrm{n}^{\circ}$ 133, 135-137, 150, 170).

Sin embargo, la falta de espacio para maniobrar estos enormes monolitos condicionaría muchas de las operaciones necesarias para el transporte, hasta el punto de determinar quizás el emplazamiento de algunos elementos gigantescos. Pensemos en los fustes de granito de las termas de Caracalla, de 36 pies de altura y 90 toneladas de peso, que en el momento de su puesta en obra, tras ser transportados en posición horizontal, tuvieron que ser elevados gracias a un complejo y voluminoso sistema de grúas diseñadas precisamente para compensar las tensiones que dichas operaciones generaban (Taylor 2006: 129, fig. 56). O pensemos también en el complicado proceso de elevación del obelisco de Tutmosis III, de 32,5 m de altura, que Constancio II colocó en el 357 d.C. sobre la espina del Circo Máximo en Roma, un proceso que nos narra Amiano Marcelino con gran detalle (17, 4, 14-15):

Para ponerlo en vertical se llevaron y alzaron un gran número de vigas, a las que se colgaron largas y pesadas cuerdas que con su gran número parecían una densa red que escondía el cielo. A esta estructura se ató aquélla auténtica montaña cubierta de figuras esculpidas y gradualmente fue elevado en alto, en suspensión y, tras permanecer suspendida por un cierto tiempo, mientras muchos millares de hombres giraban ruedas parecidas a máquinas fue finalmente colocada al centro del circo.

De hecho, si analizamos la disposición de los mayores obeliscos de Roma observamos que éstos fueron alzados en zonas o no completamente urbanizadas o fácilmente accesibles desde el Tíber y con amplios espacios a su alrededor para disponer las máquinas necesarias tanto para su transporte como para su alzado: pensemos al obelisco del circo de Calígula en el Vaticano, a los obeliscos erigidos en el Campo de Marte o al obelisco que a través de la puerta Ostiense alcanzó el Circo Máximo. De este último, como hemos visto, Ammiano Marcellino (17.4.13-15) nos detalla las dificultades derivadas de su transporte hasta Roma y de su puesta en obra, pero nada dice acerca de posibles 


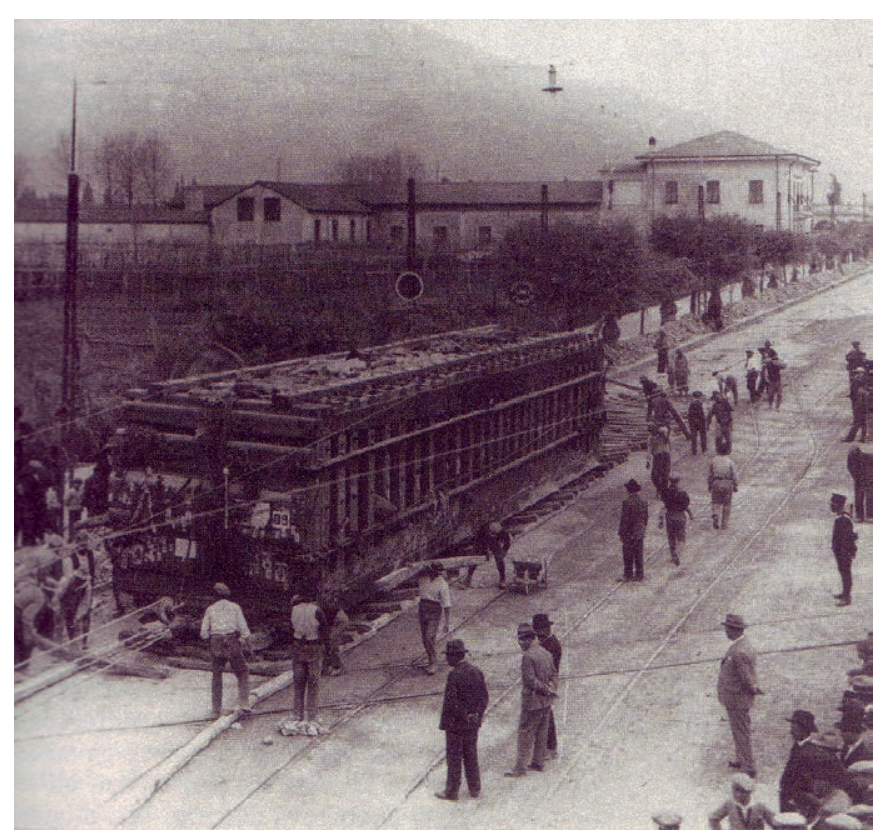

Fig. 3. Transporte del obelisco de Mussolini sobre trineos (Autor: anónimo. Wikimedia Commons).

dificultades derivadas de su transporte por el interior de la ciudad, muy probablemente porque recorrió un trayecto no densamente urbanizado entre esta puerta y el Circo Máximo que no planteó especiales dificultades. Podemos citar también, a modo de ejemplo, el proyecto diseñado por Domenico Fontana para desplazar el obelisco del Vaticano, que muestra el volumen y complejidad de los sistemas mecánicos que requerían este tipo de operaciones así como la abundante mano de obra empleada dispuesta a lo largo y ancho de un enorme espacio (Marconi 2008: 45-56). Una complejidad que se percibe también en un relieve grabado en la base del obelisco de Teodosio en Constantinopla que reproduce el propio obelisco todavía dispuesto horizontalmente en el suelo pero preparado ya, con la presencia de innumerables cuerdas y poleas, para ser alzado (Fig. 5) (Pensabene 2013: 259-260).

Además, la forma alargada de los fustes no facilitaba su maniobrabilidad, pues sus dimensiones impedían muchas veces realizar giros de $90^{\circ}$ por las calles de Roma. Más sencillo debía ser el transporte de piezas con una forma más compacta, que podían contar con la ayuda de máquinas especiales (Adam 2011: 31, fig. 33a), como las que describe Vitruvio (Libro 10).

Por tanto, y teniendo en cuenta estas premisas, dos son las posibles rutas que aquí proponemos para el transporte de los grandes fustes utilizados en el templo de Antonino y Faustina y en el Aula de Culto del Templum Pacis

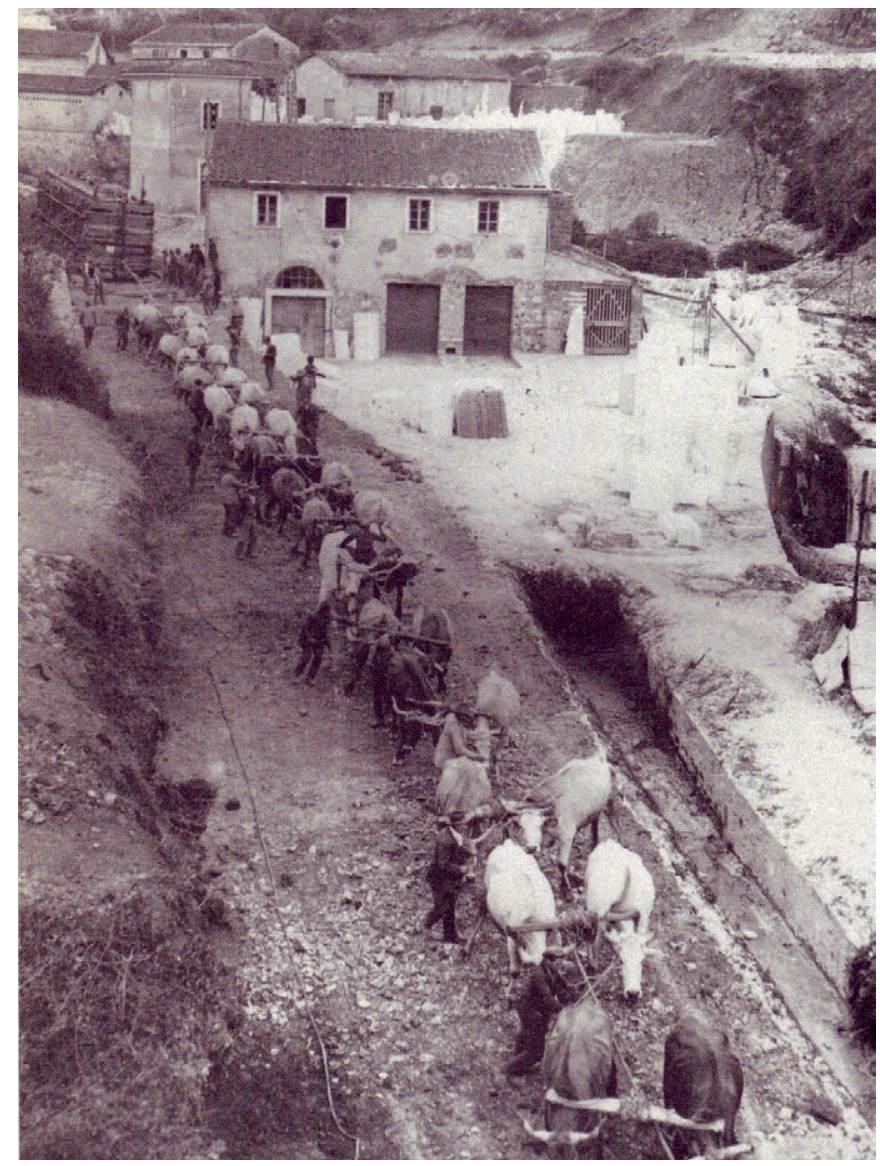

Fig. 4. Transporte del monolito del Foro Italico tirado por 100 bueyes (Autor: anónimo. Wikimedia Commons).

(Fig. 6). Estas propuestas se sustentan en las evidencias que tenemos acerca del transporte de grandes bloques, como el obelisco de Constancio II a través de la puerta Ostiense, una ruta que podría proseguir por las inmediaciones del Coliseo hasta la vía Sacra y el Foro Romano, y las marcas dejadas delante del mausoleo de Augusto por los elementos del entablamento del Panteón, que indicarían la llegada de naves cargadas con grandes bloques de mármol a través del Tíber hasta la zona del Campo de Marte, desde donde fácilmente podrían alcanzar la vía Lata y el centro de la ciudad. Este recorrido habría permitido, por ejemplo, el transporte de la columna monolítica en sienite de Antonino Pío que sabemos se alzaba en la zona de Montecitorio, cuya altura era de $50 \mathrm{pies}^{22}$. De todos

\footnotetext{
22 La inscripción, dispuesta en la base del fuste, señala que esta columna fue realizada en el noveno año del reinado de Trajano, por tanto más de 50 años antes de su primer uso por parte de Antonino Pío. En base a este dato, J. B. Ward-Perkins supone que esta columna podría haber sido fabricada para el templo del Divo Traiano, para cuya construcción muy probablemente fueron encargados algunos fustes de más de aquéllos necesarios (durante el transporte de los grandes elementos arquitectónicos algunos podían sufrir daños) (Ward-Perkins 1992: 108-110).
} 


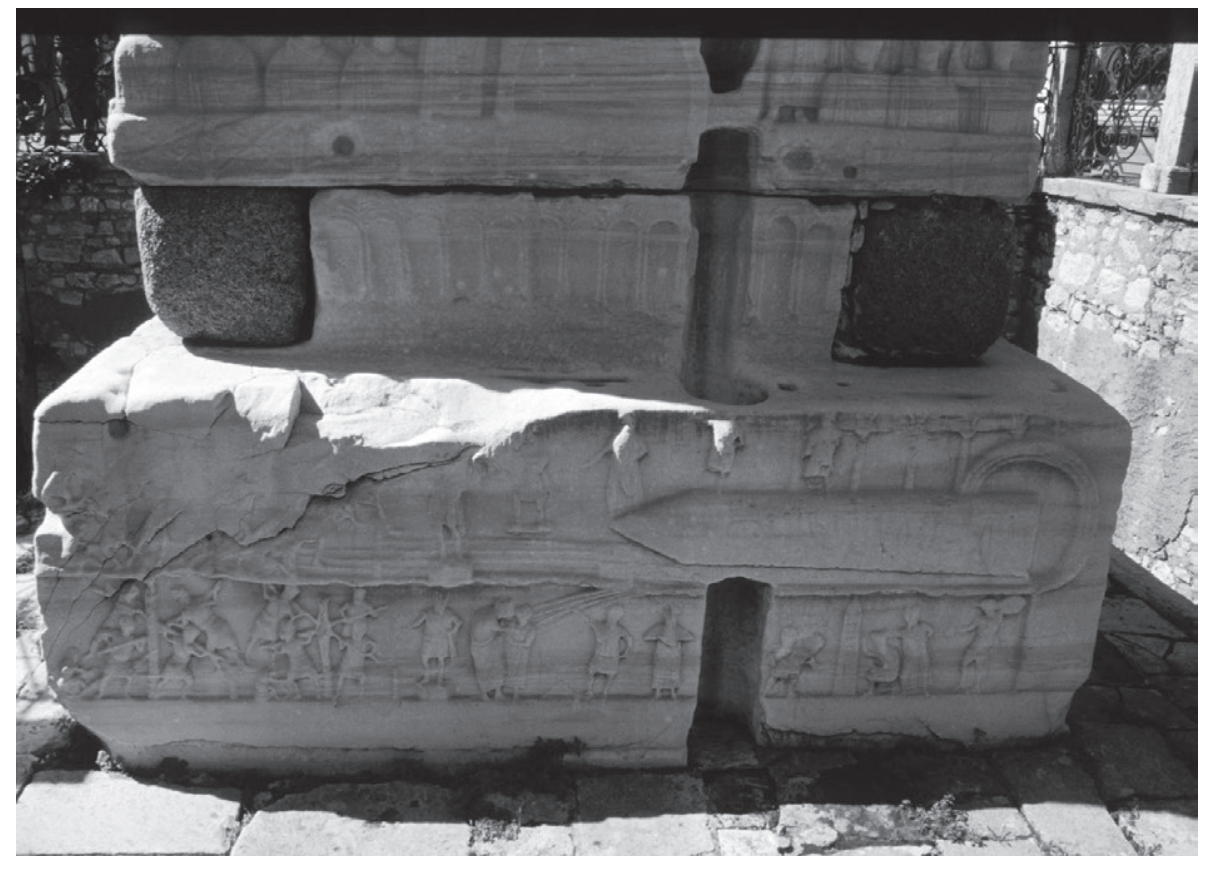

Fig. 5. Relieve en la base del obelisco de Teodosio en Constantinopla que muestra el proceso de transporte del propio obelisco. modos, no hay que perder de vista que en cada momento histórico, y en función de las características urbanas de la zona, las rutas utilizadas podrían adaptarse a las distintas necesidades; recordemos a modo de ejemplo la propuesta realizada para el transporte de las columnas utilizadas en el Foro de Trajano.

En base a estos datos podemos señalar que:

1) Las columnas del templo de Antonino y Faustina podrían haber alcanzado el centro de la ciudad bien a través de la vía Ostiense, flanqueando el circo Máximo hasta alcanzar la vía Sacra, que en este punto alcanzaba los $10 \mathrm{~m}$ de anchura, o bien a través de la vía Lata, de unos 6,5 $\mathrm{m}$ de anchura y un recorrido perfectamente rectilíneo hasta el centro de la ciudad; aunque en este caso los fustes hubiesen tenido ciertas dificultades, no insalvables, para realizar giros de $90^{\circ}$ (Fig. 7). Recordemos que la ruta propuesta para el transporte de los fustes del templo del Divo Trajano plantearía en este caso algunos problemas, como la realización de un giro de casi $90^{\circ}$ en el interior del Foro Romano, sorteando los Rostra.

2) Las columnas del Aula de Culto del Templum Pacis, mucho mayores, hubiesen tenido serias dificultades para transitar por la vía Lata, pues no hubiesen podido realizar un giro de $90^{\circ}$ por una calle de tan sólo $6,5 \mathrm{~m}$ de anchura (Fig. 7). Por tanto, es más probable que hubiesen utilizado la ruta que desde el sur permitía alcanzar la vía Sacra, mucho más ancha, flanqueando la elevación de la Velia y los "horrea Piperataria", situados donde hoy se levanta la basílica de Majencio (Coarelli 1983: 44) ${ }^{23}$. Esta hipótesis se refuerza por el hecho que los fustes fueron utilizados en época severiana, tras el incendio del 192 d.C. que distintas fuentes (Dion Cassio 72,24; Hist. Aug., Herod., 1,14) señalan que afectó al Templum Pacis, a su peristilo, a los "horrea Piperataria", al templo de Vesta y que llegó hasta la Domus Flavia. Por tanto, afectó a la zona situada al sur del monumento y muy probablemente abrió distintas brechas que facilitaron el acceso de los fustes hasta el interior del Templum Pacis, salvando el obstáculo que para ello podían representar los "horrea Piperataria", en parte destruidos por este incendio. S. Fogagnolo y F. M. Rossi sugieren sin embargo una alternativa, similar a la mencionada precedentemente para los fustes del Foro de Trajano, que pasaría a través del Velabro y el vicus Iugarius (vía de S. Teodoro) hasta alcanzar el Foro Romano, desde donde los fustes llegarían a su destino o bien flanqueando el templo de Antonino y Faustina o atravesando el vicus ad Carinas (Fogagnolo y Rossi 2010: 103, fig. 21). Una ruta que plantearía algunos problemas, como hemos mencionado anteriormente.

Con este estudio hemos pretendido únicamente presentar algunas posibles soluciones a los complejos problemas

\footnotetext{
Sobre las estructuras existentes debajo de la basílica de Majencio ver:
} Amici 2006: 21-27. 


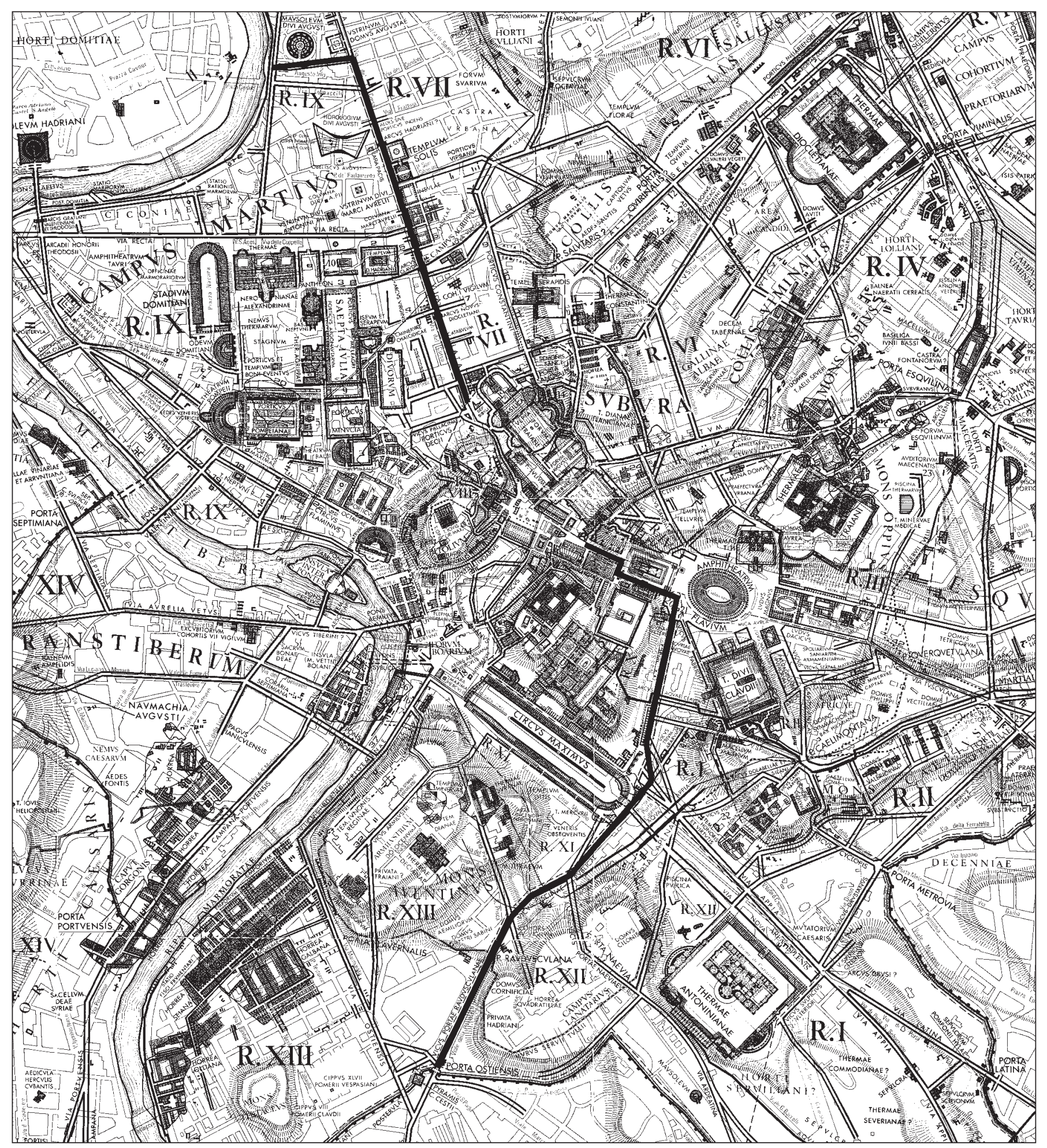

Fig. 6. Dos posibles rutas de acceso de los fustes gigantescos al centro urbano de Roma.

que planteaba el transporte de los fustes gigantescos por el interior de la trama urbana de la ciudad. No obstante, es necesario tener presente que no existiría un único modo de resolver las dificultades derivadas del transporte de estos fustes, y que cada proyecto arquitectónico podía adaptar las diversas soluciones posibles. Tampoco hemos de excluir la posibilidad de la destrucción parcial de algunas construcciones para permitir el paso de estos elementos gigantescos. Recordemos ahora como el transporte por las calles de Roma de algunas columnas de 38 pies de altura 


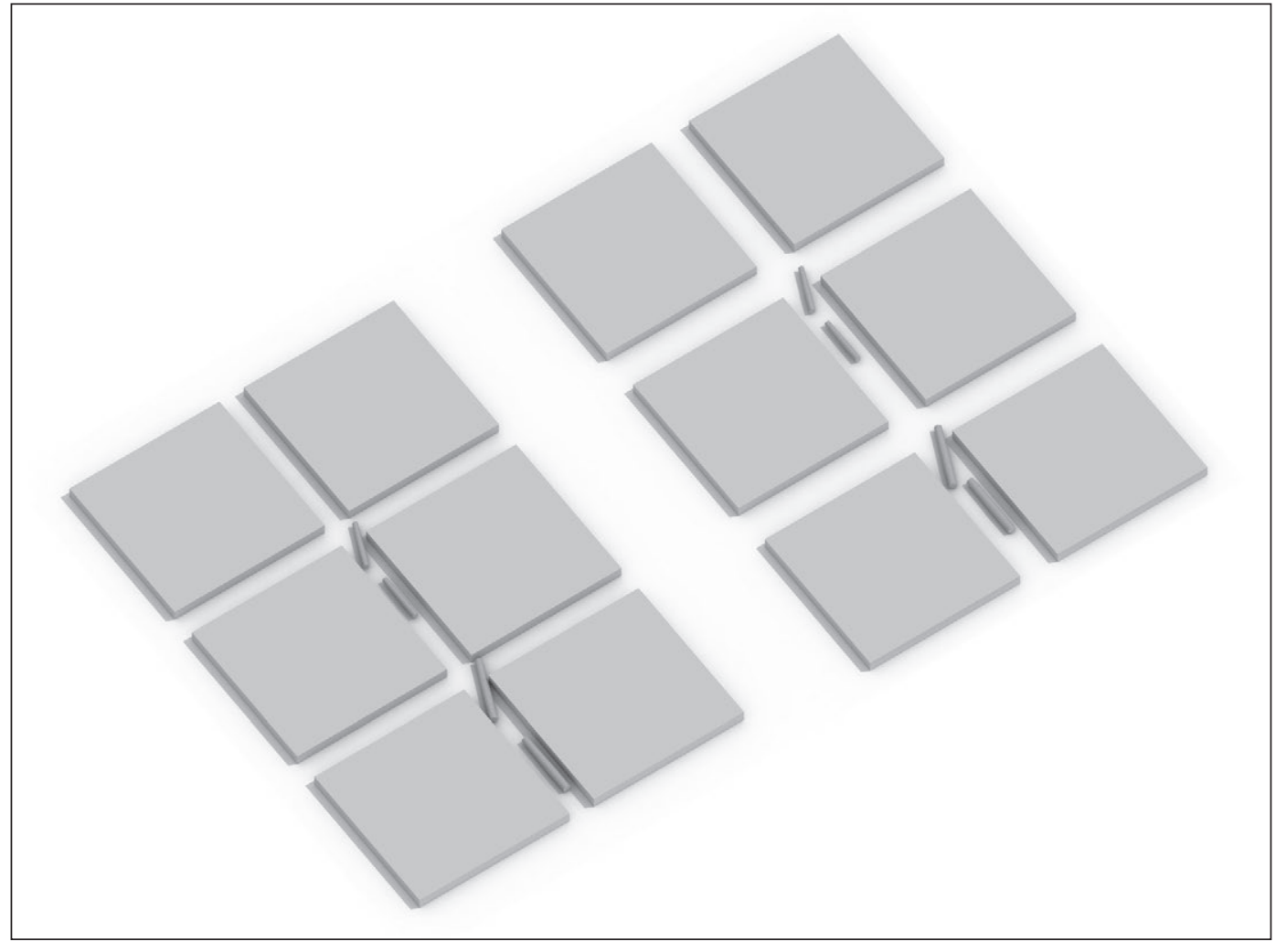

Fig. 7. Simulación del paso de los fustes gigantescos por las calles de Roma. A la izquierda la reconstrucción de la anchura de la vía Lata, de $6,5 \mathrm{~m}$; en la parte superior los fustes del templo de Antonino y Faustina y en la parte inferior los fustes del Templum Pacis. A la derecha la reconstrucción de la anchura del tramo de la vía Sacra en el Foro Romano, de unos $10 \mathrm{~m}$; en la parte superior los fustes del templo de Antonino y Faustina y en la parte inferior los fustes del Templum Pacis. dañó algunas cloacas que fueron posteriormente reparadas (Barresi 2000: 340). El transporte de los fustes era, por tanto, una de las operaciones más delicadas vinculadas al proceso constructivo, sobretodo en el caso de la arquitectura gigantesca. Debido a ello existían leyes que penalizaban a los encargados de su desembarco y transporte si durante estas maniobras malmetían las costosísimas columnas (Digest. 19.2.25.7) (Russell 2008: 113; Pensabene 2013: 148).

\section{CONCLUSIONES}

El transporte de enormes fustes monolíticos por las calles de Roma debía ser un espectáculo digno de admiración, como muestran algunas fuentes clásicas. Las dificultades que planteaban estas operaciones eran muy numerosas, hasta el punto, hemos visto, de determinar la posición de algunas construcciones; recordemos la disposición de algunos de los mayores obeliscos de Roma.

A pesar de estas dificultades, la construcción del puerto de Claudio, y sucesivamente del de Trajano (con el Canale Romano del que recientemente se ha precisado su recorrido y dimensiones), facilitaron muy probablemente que las columnas más grandes y pesadas remontasen el Tíber hasta el interior de la ciudad.
De hecho, no parece casual que los primero fustes monolíticos gigantescos documentados en Roma sean todos posteriores a la construcción del puerto de Claudio. Es cierto que los fustes podrían haber sido transportados por tierra: pero en este caso los gastos derivados de su transporte hubieran sido mucho más elevados —el coste del transporte por tierra era aproximadamente 8 veces más elevado que el realizado por río (Russell 2008: 114) _ y, por tanto, menos conveniente. Estas circunstancias - mayores dificultades técnicas y mayor coste económico - pudieron haber favorecido la división de los fustes en tambores que predominó durante todo el periodo julio-claudio.

Otra observación que podría añadirse a cuánto hemos dicho en relación al frecuente uso de fustes de enormes dimensiones en la gran arquitectura de Roma - recordemos su capacidad de generar asombro y de comunicar el poder del emperador o de los comitenteses que éstos simplificaban también algunas operaciones del proceso constructivo: bastaba por ejemplo una sola operación de carga y descarga para cada fuste (podemos citar en este sentido la columna cuadrilobulada procedente del Canal de Fiumicino, formada por cuatro fustes importados todavía unidos en un mismo bloque de mármol pavonazzetto) (Fig. 8) (Pensabene 1994: 73, nº 19, 


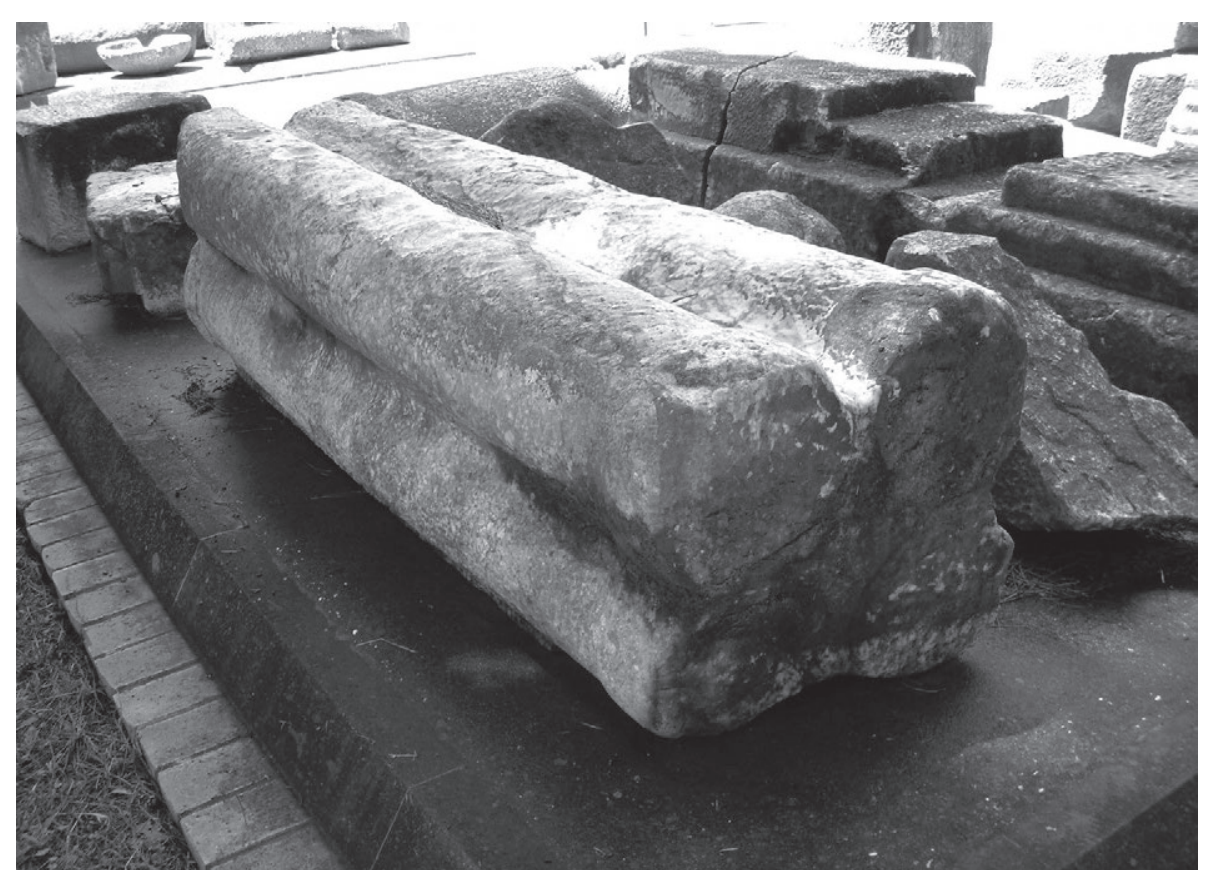

Fig. 8: Columna cuadrilobulada del Canal de Fiumicino. figs. 89-91) y su uso permitía además realizar de manera más rápida algunas operaciones de fabricación y puesta en obra: la mano de obra utilizada en las fases de extracción, elaboración y puesta en obra de un gran bloque de piedra era inferior a la necesaria para reproducir estas operaciones en un número mayor de pequeños bloques, el uso de bloques pequeños requería la repetición mecánica de algunas acciones que se multiplicaban para cada uno de ellos, la puesta en obra de grandes monolitos, aun siendo más compleja técnicamente, permitía una mayor rapidez en la ejecución. (Pensabene y Domingo 2014: 130). La simplificación de estas operaciones podían implicar un ahorro de hasta $1 / 3$ del coste del proceso constructivo (Bessac 2010: 185-187).

\section{BIBLIOGRAFÍA}

Adam, C. E. P. 2001: "Who bore the burden? The organization of stone transport in Roman Egypt", en D. J. Mattingly; J. Salmon (eds.), Economies beyond agriculture in the classical world, pp. 171-192. Routledge, London-New York.

Adam, J.-P. 2011: La construction romaine. Matériaux et techniques. Picard, Paris.

Amici, C. M. 1991: Il Foro di Cesare, Firenze.

Amici, C. M. 2006: "From project to monument", en C. Giavarini (ed.), The Basilica of Maxentius. The Monument, its Materials, snd Stability, pp. 2174. L'Erma di Bretschneider, Roma.

Barresi, P. 2000: “Architettura pubblica e munificenza in Asia Minore. Ricchezza, costruzioni e marmi nelle provincie anatoliche dell'Impero", Medediterraneo Antico, III, I, pp. 309-368.

Bernard, H., Bessac, J.-C., Mardikian, P. y Feugère, M. 1998: "L'épave romaine de marbre de Porto Novo", Journal of Roman Archaeology, 11, pp. 53-81.
Bessac, J.-C. 2010: "Le mégalithisme antique au proche-orient: idées reçues et données nouvelles", Syria, 87, pp. 173-190.

Bianchi, E. y Meneghini, R. 2002: "Il cantiere costruttivo del foro di Traiano", $R M, 109$, pp. 395-417.

Boato, A. 2007: "Organizzazione delle forniture e mercato dei materiali da costruzione a Genova (secoli XV-XVIII)", Mélanges de l'École Française de Rome: Italie et Méditerranée, 119.2, pp. 215-233.

Bülow-Jacobsen, A. 2009: Mons Claudianus. Ostraca Graeca et Latina IVThe Quarry Texts: O. Claud. 632-896. Documents de Fouilles de 1'Institut Français d'Archéologie Orientale, 47, Cairo.

Carcopino, J. 2007: La vita quotidiana a Roma. Laterza, Bari.

Cifani, G. 2010: "I grandi cantieri della Roma arcaica: aspetti tecnici ed organizzativi", en S. Camporeale, H. Dessales y A. Pizzo (eds.), Arqueología de la Construcción II. Los procesos constructivos en el mundo romano: Italia y provincias orientales, (Certosa di Pontignano, Siena 2008), pp. 35-49. CSIC, Madrid-Mérida.

Coarelli, F 1977: "Il Campo Marzio occidentale. Storia e topografia", $M E-$ FRA, 89.2, pp. 807-846.

Coarelli, F. 1983: Il Foro Romano. Periodo Arcaico. Quasar, Roma.

Coarelli, F. 1999: "Rostra (età repubblicana)", en LTUR, vol. 4, pp. 212-214. Edizioni Quasar, Roma.

Coarelli, F. 2012: Roma, Guide Archeologiche Laterza. Laterza, Roma.

DeLaine, J. 1997: The Baths of Caracalla. A study in the design, construction, and economics of large-scale building projects in imperial Rome, (Journal of Roman Archaeology, suppl. 25). Portsmouth.

DeLaine, J. 2002: "The temple of Hadrian at Cyzicus and roman attitudes to exceptional construction", Papers of the British School at Rome, LXX, pp. 205-230.

Dubois, C. 1908: Étude sur l〉administration et l`exploitation des carrières marbres, porfyre, granite, etc., dans le monde romain. Fontemoing, Paris.

Fant, J. C. 2012: "Contracts and costs for shipping marble in the roman Empire”, en A. Gutiérrez, P. Lapuente y I. Rodà (eds.), Interdisciplinary Studies on Ancient Stone. Proceedings of the IX ASMOSIA Conference, (Tarragona 2009), pp. 528-532. Institut Català d'Arqueologia Clàssica, Tarragona.

Filippi, F. 2014: "Novi dati sulla topografia antica dai saggi per la Metro C nell'area del Campo Marzio Occidentale: il Ginnasio di Nerone (?) e l'Euripus", en J.-F. Bernard (dir), Piazza Navona, ou Place Navone, la plus belle \& la plus grande. Du stade de Domitien à la place moderne, histoire d'una évolution urbaine, pp. 53-70. École Française de Rome 2014. 
Fogagnolo, S. y Rossi, F. M. 2010: "Settore meridionale del Foro della Pace: l'impatto del cantiere di restauro Severiano, corrispondenze e differenze rispetto al progetto originario", en S. Camporeale, H. Dessales y A. Pizzo (eds.), Arqueología de la Construcción II. Los procesos constructivos en el mundo romano: Italia y Provincias Orientales, (Certosa di Pontignano, Siena 2008), pp. 93-104. CSIC, Madrid-Mérida.

Giuliani, C. F. 2015: "Problemi costruttivi del Pantheon e della c.d. Basilica Neptuni", en F. Filippi (a cura di), Campo Marzio. Nuove ricerche. Atti del Seminario di Studi sul Campo Marzio, (Roma 2013), pp. 143-177. Edizioni Quasar, Roma.

Haselberger, L. 1994: "Ein Giebelriss der Vorhalle des Pantheon: Die Werkrisse vor dem Augustusmausoleum", en RM, CI, pp. 279-308.

Hopkins, K. 1983: "Models, Ships and Staples", en P. Garnsey y C. R. Whittaker (eds.), Trade and Famine in Classical Antiquity, pp. 84-109. Cambridge philological society, Cambridge.

Jodin, A. 1987: Volvbilis Regia Ivbae. Contribution à l'étude des civilisations du Maroc antique préclaudien. Diffusion De Boccard, Paris.

Maischberger, M. 1997: Marmor in Rom. Anlieferung, Lager-und Werkplätze in der Kaiserzeit, Palilia, 1. L. Reichert, Wiesbaden.

Marano, Y. A. 2014: "Le cave di marmo nella tarda antichità: aspetti organizzativi e produttivi”, en J. Bonetto, S. Camporeale y A. Pizzo (eds.), Arqueología de la Construcción IV. Las canteras en el mundo antiguo: sistemas de explotación y procesos productivos, (Padova 2012), pp. 413427. CSIC, Mérida.

Marconi, N. 2008: "L'eredità tecnica di Domenico Fontana e la Fabbrica di San Pietro: tecnologie e procedure per la movimentazione dei grandi monoliti tra '500 e '800", en M. Fagiolo y G. Bonaccorso (a cura di), Studi sui Fontana: una dinastia di architetti ticinesi a Roma tra Manierismo e Barocco, pp. 45-56. Gangemi ed., Roma.

Medaglia, S., Beltrame, C. y Lazzarini, L. 2013: "La navis marmorum di età romana "Punta Scifo D" (Crotone). Risultati preliminari della prima campagna di indagini subacquee", Rivista di Archeologia, XXXVII, pp. $137-165$.

Meneghini, R., Corsaro, A. y Pinna, B. 1999: "Il Templum Pacis alla luce dei recenti scavi”, en F. Coarelli (a cura di), Divus Vespasianus. Il bimillenario dei Flavi, pp. 190-201. Editoriale, Roma.

Patterson, J. R. 1999: "Via Lata", Lexicon Topographicum Urbis Romae, V, Roma, pp. 139-140.

Pensabene, P. 1994: Le vie del marmo. I blocchi di cava di Roma e Ostia: il fenomeno del marmo nella Roma antica, (Itinerari ostiensi 7). Ministero per i Beni Culturali, Roma.

Pensabene, P. 2013: I marmi nella Roma antica. Carocci, Roma.

Pensabene, P. y Domingo, J. Á. 2014: "Blocchi giganteschi di cava nell'architettura pubblica di Roma e delle provincie occidentali", en J. Bonetto, S. Camporeale y A. Pizzo (eds.), Arqueología de la Construcción IV. Las canteras en el mundo antiguo: sistemas de explotación y procesos productivos, (Padova 2012), pp. 117-134. CSIC, Mérida.

Pegoretti, G. 1869: Manuale pratico per l'estimazione dei lavori architettonici, stradali, idraulici e di fortificazione per uso degli ingegneri ed architetti. Tipografia di Domenico Salvi e C. ${ }^{\circ}$, Milano.
Pentiricci, M. 2009: "Il settore occidentale del Campo Marzio tra l'età antica e l'altomedioevo", en Ch. Luitpold, M. Pentiricci (a cura di), L'antica basilica di San Lorenzo in Damaso. Indagini archeologiche nel Palazzo della Cancelleria (1988-1993). Volume I- Gli Scavi, pp. 15-75. Roma.

Prisset, J.-L. 2008: "Les besoins en matérieux, les contraintes d'approvisionnement et la durée d'un chantier de construction. Réflexions à partir du portique nord de Saint-Romain-en-Gal (France)", en S. Camporeale, H. Dessales, A. Pizzo (eds.), Arqueología de la Construcción I. Los procesos constructivos en el mundo romano: Italia y provincias occidentales (Mérida 2007), pp. 125-139. CSIC, Mérida.

Rathbone, D. 2003: "The financing of maritime commerce in the roman empire, I-II AD", en E. Lo Cascio (a cura di), Credito e moneta nel mondo romano. Atti degli Incontri capresi di storia dell'economia antica, (Capri 2000), pp. 197-229. Edipuglia, Bari.

Rizzo, S. 2001: "Indagini nei fori Imperiali. Oroidrografia, foro di Cesare, foro di Augusto, templum Pacis”, Römische Mitteilungen, CVIII, pp. 215-244.

Russell, B. 2008: "The dynamics of stone transport between the Roman Mediterranean and its hinterland", Facta, 2, pp. 107-126.

Russell, B. 2011: "Lapis transmarinus: stone-carrying ships and the maritime distribution of stone in the Roman Empire", en D. Robinson y A. Wilson (eds.), Maritime Archaeology and Ancient Trade in the Mediterranean, (OCMA Monograph 6), pp. 139-155. Oxford Centre for Maritime Archaeology, Oxford.

Russell, B. 2013: The economics of the Roman Stone Trade. Oxford University Press, Oxford.

Salomon, F., Goiran, J.-Ph., Bravard, J.-P., Arnaud, P., Djerbi, H., Kay, S. y Keay, S. 2014: “A harbour-canal at Portus: a geoarchaeological approach to the Canale Romano: Tiber delta, Italy", Water Hist, 6, pp. 31-49.

Theodore Peña, J. 1989: "P. Giss.69: evidence for the supplying of stone transport operations in Roman Egypt and the production of fifty-foot monolithic column shafts", Journal of Roman Archaeology, 2, pp. 126-132.

Taylor, R. 2006: Los constructores romanos. Un estudio sobre el proceso constructivo. Akal, Madrid.

Verduchi, P. 1999: “Rostra Augusti”, en LTUR, vol. 4, pp. 214-217. Edizioni Quasar, Roma.

Ward-Perkins, J. B. 1992: "Columna Divi Antonini", en H. Dodge; B. Ward-Perkins (eds.), Marble in Antiquity. Collected Papers of J. B. Ward-Perkins, pp. 107-114. British School at Rome, London.

Wilson Jones, M. 2009: Principles of Roman Architecture. Yale University Press, Singapore.

\section{FICHA TÉCNICA}

Las fotografías e imágenes que acompañan el texto, a excepción del la Fig. 3 y 4, han sido realizadas por los autores de este artículo. 